\title{
A brief history of homeopathy
}

\author{
Irvine Loudon
}

$J$ R Soc Med 2006;99:607-610

One of the most striking features of unorthodox medicine_-variously described as quackery, irregular medicine, fringe medicine, or complementary and alternative medicine (CAM) - has been its ability to survive for centuries in a very wide variety of forms. Although it has changed enormously with the passage of time, unorthodox medicine has always has been a rich source of disputes, claims and counter-claims, and accusations of fraud. ${ }^{1,2}$ One might expect that unorthodox medicine as a whole would have diminished as a result of the spectacular advances in regular medicine during the second half of the twentieth century, but that does not seem to be the case. In fact we will never really know how many people in the past consulted unorthodox practitioners instead of, or in addition to, consulting the orthodox; we don't even know today. But we do know that before the mid-nineteenth century the irregular practitioners for whom the derogatory term 'quacks' is appropriate, were used by a large proportion of the population. ${ }^{3}$

Most of these pre-1850 quacks tended to specialize. Some were bone-setters, others claimed to cure venereal disease without the use of mercury. A 'Dr' Taylor of Beverley in Gloucester arranged to attend regularly at three public houses to which patients only had to send their urine and he would tell at once whether they were curable or not. There were self-styled oculists who specialized in the treatment of cataract and curers of 'cancer without operation'. One of the latter, calling himself the 'High German Dr Symon', invited you to visit his house and see for yourself 'a cancer of the armpit of five pieces of 12 and one half ozs weight' which he claimed to have removed.

Most of these irregulars were uneducated or even illiterate and only a minority were full-time healers. They usually had regular jobs, such as blacksmith, farrier, grocer, butcher, cheese-monger, cobbler, cutter and mechanic. They often claimed the patronage of the 'great and the good.' Dr Scott's Bilious and Liver Pills were used by 'the Dukes of Devonshire, Northumberland and Wellington, Angelsea [sic], and Hastings, and the Earls of Pembroke, Essex and Oxford' while 'Dr' Lambert at 36 High Street, Borough, London, claimed to 'visit the well-to-do in the West Indies, the Isles of Scilly, London, Nottingham, Derby, Norwich,

Medical Historian and Honorary Fellow, Green College, Oxford

E-mail: irvine.loudon@green.ox.ac.uk
Lincoln, Boston, Gloucester, Wolverhampton, Lichfield, Stourbridge' and, for good measure, 'almost every other town in the Kingdom.' 4 These irregulars had one thing in common: they had little, if any, interest in or understanding of orthodox medicine in their time. Their sole aim was to make money. They were empirics for whom the derogatory term 'quackery' is appropriate. ${ }^{5}$

But a major change in irregular practice occurred in the first half of the nineteenth century when, as an orthodox practitioner remarked: 'the old-fashioned quack with his farrago of receipts who seldom visited the same neighbourhood but at very long intervals in order to avoid recognition . . . this class of practitioner is fast coming to a close.' It was being replaced by 'literate and educated empirics who read books.' ${ }^{6}$ This remark signalled the emergence of a new form of unorthodox medicine, which formed the basis of what is today called CAM.

\section{THE BIRTH OF COMPLEMENTARY AND ALTERNATIVE MEDICINE}

The essence of the change was a rebellion against orthodox medical science as taught and practised in the teaching hospitals, and the introduction of a series of radically different but all-embracing beliefs on the nature and treatment of disease. The empirical quack continued in the background and still exists today, although in an attenuated form. But the new irregulars - the literate 'book-reading' practitioners - were usually educated men and often medically qualified.

They were therefore not so much quacks (although frequently derided as such) as practitioners for whom the terms 'alternative' or 'complementary' is more appropriate. Indeed, supporters of CAM have good reason to object to the term 'quackery' being linked in any way with such practices as homeopathy, osteopathy, chiropractic, acupuncture and herbalism. It would be impossible to review the history of all the current forms of alternative medicine, so I am confining this paper to one of the earliest and still the most frequently used unorthodox system: homeopathy.

\section{HOMEOPATHY}

While it can scarcely compare in antiquity with Chinese or Indian medicine, homeopathy is the longest established CAM to have arisen in Europe. ${ }^{7}$ It was founded by Samuel 
Hahnemann (1755-1843), who grew up in Meissen in Germany, received his medical degree in Erlangen in 1779, and died a millionaire in Paris in 1843. During his first fifteen years as a physician Hahnemann struggled desperately to make a living. One day, however, he made a discovery. He started to take regular doses of cinchona or 'the bark' (i.e. quinine). This, he said, produced all the symptoms of intermittent fever (malaria) but to a mild degree and without the characteristic rigors of that disease. This led Hahnemann to an idea which was published in 1796 as Essay on a New Principle for Ascertaining the Curative Power of Drugs, which was followed in 1810 by his famous work The Organon of the Healing Art. ${ }^{1}$

Hahnemann believed that if a patient had an illness, it could be cured by giving a medicine which, if given to a healthy person, would produce similar symptoms of that same illness but to a slighter degree. Thus, if a patient was suffering from severe nausea, he was given a medicine which in a healthy person would provoke mild nausea. By a process he called 'proving', Hahnemann claimed to be able to compile a selection of appropriate remedies. This led to his famous aphorism, 'like cures like', which is often called the 'principle of similars'; and he cited Jenner's use of cowpox vaccination to prevent smallpox as an example.

The differences between orthodox medicine and homeopathy could hardly be more vivid. From its beginning homeopathy always began with a long consultation, lasting at least an hour, in which all aspects of the patient's illness and life were discussed - homeopaths like to stress that they practise 'holistic medicine' - and the appropriate treatment chosen. In contrast, during the first half of the nineteenth century, when homeopathy was becoming established, orthodox medicine was immersed in the belief that advances in understanding disease could only come from a detailed correlation of symptoms and signs of the sick patient on the ward, and the findings at autopsy: clinico-pathological correlation. As Bichat famously put it put it at the very end of the eighteenth century:

'For twenty years from morning to night you have taken notes at patients' bedsides . . . which, refusing to yield up their meaning, offer you a succession of incoherent phenomena. Open up a few corpses: you will dissipate at once the darkness that observation alone could not dispel.' ${ }^{8}$

Clinico-pathological correlation demanded the understanding of a very long and complex collection of diseases accompanied by heated debates between the contagionists and the anti-contagionists. This was way beyond the comprehension of the general public. Moreover, medical treatment was to a large extent crude and ineffective, consisting largely of potentially dangerous polypharmacy, purging, and profuse blood-letting.

Hahnemann showed no interest in detailed pathology, and none in conventional diagnosis and treatment. He was only interested in the principles of homeopathic medicine which he used to name the illness. ${ }^{2}$ Classical homeopathy was therefore seen by its supporters as an attractively safe system, simple, easy to understand, and centred on the patient as a whole and not on pathological lesions. This goes a long way to explain why homeopathy was popular. ${ }^{9}$

But there was one aspect of homeopathy which, from the time it was first announced in about 1814, led to open warfare between orthodox medicine and homeopathy. This was the result of Hahnemann's belief that drugs should be given in a dose which only just produced the slightest symptoms of the disease which was being treated. To achieve this aim, Hahnemann diluted his medical preparations to such an astonishing extent that if one assumes that that the substance he employed was completely soluble, by only the fourth dilution the ratio of the medicine to the solution would be 1:100000000. The physician and poet Oliver Wendell Holmes (1809-1894) in the USA, always a master of ridicule, said that Hahnemann's dilution would take 'the waters of ten thousand Adriatic seas.' 1 But Hahnemann insisted that homeopathic medicines retained their therapeutic power provided you shook the preparation violently during the process of dilution - a process Hahnemann named as 'potentization' by which every homeopathic medicine not only retained or even increased its therapeutic power, but persisted as a 'dematerialized spiritual force'. To orthodox practitioners this was sheer nonsense. ${ }^{10}$ Hahnemann claimed that by his methods he could cure all or nearly all acute diseases. To make matters worse, he announced in 1828 that all, or nearly all, chronic diseases were caused by 'the itch' (scabies).

Whereas Hahnemann claimed that homeopathy could cure all or virtually all diseases, his followers modified these claims in the hope of becoming accepted by orthodox medical practitioners. One of the first institutions devoted to homeopathy was the American Institute of Homeopathy, founded at the end of the nineteenth century, when it seems that 'a rapprochement between homeopaths and conventional physicians gradually unfolded. Homeopaths adopted new orthodox treatments . . . while allopaths [regular orthodox physicians] borrowed homeopathic remedies . . . In 1903, after long antagonism, the American Medical Association . . . invited homeopaths to join [the Association].' 9 The Food, Drug and Cosmetic Act of 1939 in the USA allowed homeopathic medicines to be sold openly on the market. Five homeopathic hospitals were founded in Britain, the two largest (in London and Glasgow) having in-patient units. Today the ten most common diseases treated by homeopaths are (in order of frequency) asthma, depression, otitis media, allergic rhinitis (hay fever), headache and migraine, neurotic disorders, non-specific allergy, dermatitis, arthritis and hypertension.

There seems little doubt there has been a remarkable revival of homeopathy since the 1960 s and 1970s in many 
countries, but especially the USA where, in 2002, it was estimated that the number of patients using homeopathic remedies had risen by $500 \%$ in the previous seven years, mostly by purchasing over-the-counter remedies. In the USA patients seen by homeopaths tended to be more affluent, more frequently white, present more subjective symptoms, and to be younger than patients seen by conventional physicians. ${ }^{9}$ In Britain a survey by the BBC in 1999 found that $17 \%$ of 1204 randomly selected adults had used homeopathy within the past year (this includes homeopathic remedies bought over the counter) and another survey in 1998 estimated that there were 470000 recent users of homeopathy in the UK. It is likely that most patients in the UK who use complementary medicine are largely middle class and middle aged. ${ }^{11}$ One of the well known features of homeopathy is that from the nineteenth century to today it has been firmly supported by royalty and the aristocracy. Edward, Prince of Wales was the patron of the London Homeopathic Hospital, while the Duke of York, later King George VI, gave the title 'Royal' to the hospital. He also named one of his race-horses 'Hypericum' after a homeopathic remedy. He entered it for the Thousand Guinea Stakes at Newmarket in 1946 and it won. ${ }^{12}$

\section{IS HOMEOPATHY EFFECTIVE?}

If you rely on the personal experience of patients, there are a large number of people who will claim, usually with great certainty, that they had been cured or at least helped by homeopathy when orthodox medicine had failed. One can see why. The system is easy to understand and seems safe. The long consultation is, per se, therapeutic, although it is seldom realized that a succession of shorter consultations with an orthodox and sympathetic general practitioner can soon add up to an hour, with the added advantage that the series of consultations allows observation of the development or disappearance of a disease over time. This is especially important since many of the diseases treated by homeopaths are either transient and disappear spontaneously, or they are cyclical, consisting of a series of attacks followed by spontaneous remissions. If a visit to a homeopath happens to be followed by a remission or the total disappearance of a disease, homeopathic medicine gets the credit.

If there was ever a medical system which cried out for a careful scientific trial it is homeopathy. One of the early trials, carried out in 1835 , is astonishing because it was very close to a double-blind, randomized controlled trial, undertaken with great care long before the mid-twentieth century when most of us believed that such randomized trials were first devised and carried out. It showed, incidentally, that homeopathy was ineffective. ${ }^{13}$ This was followed by such a long series of clinical trials and systematic reviews, stretching up to the present time, that to review all of them would take up more space than the whole of this paper; but a useful account of clinical trials of homeopathy in the nineteenth century was published very recently. ${ }^{14}$

Some homeopathic practitioners argue that carrying out randomized controlled trials is an appropriate activity for orthodox medicine but inappropriate for homeopathy, where effectiveness should only be judged by patient satisfaction. Where clinical trials and systematic reviews have been carried out, however, the results remain uncertain. A few seemed to show that homeopathy was effective, but only slightly; a majority showed that homeopathy had no therapeutic effect. Unfortunately many of the trials included in systematic reviews were less than perfect in design, application or sample size.

A recent authoritative paper concluded that 'the evidence of the effectiveness of homeopathy for specific clinical conditions is scant, is of uneven quality, and is generally of poorer quality than research done in allopathic (mainstream) medicine.' Nevertheless 'when only high quality studies have been selected . . . a surprising number show positive results' although 'even the best systematic reviews cannot disentangle components of bias in small trials.' These authors conclude that 'more and better research is needed, unobstructed by belief or disbelief in the system. ${ }^{\prime 9}$

When one recalls the underlying beliefs of the homeopathic system, such as the process of extreme dilution with the transformation of a drug into a 'dematerialized spiritual force', a totally neutral and 'unobstructed' attitude may be impossible. We can, however, be reasonably certain that in the context of the total provision of medical care, homeopathy has played and still plays a large part, judged by the number of patients who believe, rightly or wrongly, that homeopathy has helped them.

The late Sir Douglas Black should have the last word. In a very balanced article on complementary medicine, he wrote:

'Although mainstream medical intervention is critical in only a minority of episodes of illness, in those particular episodes it is critical indeed; and I would plead that at least in acute illness, and possibly in any illness, "complementary" medicine should also be subsequent to an assessment of the clinical situation by competent "orthodox" means.'

Competing interests None declared.

\section{REFERENCES}

1 Gevitz N. Unorthodox medical theories. In: Bynum WF, Porter R (eds). Companion Encyclopaedia of the History of Medicine London: Routledge, 1993:603-33

2 Fulder S. The Handbook of Alternative and Complementary Medicine. London: Hodder and Stoughton, 1996 
3 Harrison E. The Ineffective State of the Practice of Physic. London: 1806

4 Forbes J. On the patronage of quacks and impostors by the upper classes of society. British and Foreign Medical Review 1846;21:533-40

5 Loudon I. 'The Vile Race of Quacks with which this Country is Infested.' In: Bynum WF, Porter R (eds). Medical Fringe and Medical Orthodoxy 1750-1850. London: Croom Helm, 1987:42

6 'Omega'. Remarks on quackery. Provincial Medical and Surgical Journal $1840-41 ; 1: 418-9$

7 Black D. Complementary Medicine. In: Walter J, Walton L, Jeremiah A, Barondess JA, Lock S (eds). The Oxford Medical Companion. Oxford: Oxford University Press, 1994

8 Bynum WF. Science and the Practice of Medicine in the Nineteenth Century. Cambridge: Cambridge University Press, 1994:30
9 Jonas WB, Kaptchuck T, Linde K. A critical view of homeopathy. Ann Intern Med 2003;138:393-9

10 Kaptchuck T. Intentional ignorance a history of blind assessments and placebo controls in medicine. Bull Hist Med 1998;72:401

11 Anon. Homeopathy. Effective Health Care 2002;7:2

12 Babington Smith C. Champion of Homeopathy. The Life of Margery Blackie. London: John Murray, 1986:38

13 Stolberg M. Inventing the randomized double-blind trial: The Nuremberg salt test of 1835. J Roy Soc Med 2006;99:643-4. A longer version of this paper is available at http:jameslindlibrary.org

14 Dean ME. 'An innocent deception': placebo controls in the St Petersburg homeopathy trial. J Roy Soc Med 2006;99:375-6. A longer version of this paper is available at http:jameslindlibrary.org 